\title{
The Research of Thermal Operations in the Equipment of Continual Casting \& Aluminum Extrusion in Transitional Mode
}

\author{
Aleksandr P. Skuratov, \\ Aleksandr S. Potapenko and Yuri V. Gorokhov* \\ Siberian Federal University \\ 79 Svobodny, Krasnoyarsk, 660041, Russia
}

Received 15.11.2016, received in revised form 04.01.2017, accepted 06.02.2017

There have being observed the parameters of technological process of non-ferrous metals continual casting \& extrusion. There are presented the results of the research of thermal processes flowing in the carousel-type equipment while continual casting \& extrusion of industrial aluminum. There have been revealed the characteristics and period of the transitional process from the equipment cold start to its steady conditions of work. With applying of the software "Ansys CFX" there has been designed the 3-D computer model of heat-exchange in this experimental-industrial equipment. As a result of mathematical modeling there has been found a necessary rotation angle of a crystallizer that provides a required nominal temperature of aluminum allow solidification under steady condition of the equipment operation.

Keywords: experimental-industrial equipment, continual casting \& extrusion, heat-exchange, aluminum allow, solidification, experiment, computer model.

Citation: Skuratov A.P., Potapenko A.S., Gorokhov Yu.V. The research of thermal operations in the equipment of continual casting \& aluminum extrusion in transitional mode, J. Sib. Fed. Univ. Eng. technol., 2017, 10(3), 337-345. DOI: 10.17516/1999494X-2017-10-3-337-345.

(c) Siberian Federal University. All rights reserved

* Corresponding author E-mail address: a.skuratov@mail.ru, komvzvodt-81@mail.ru 


\title{
Исследование тепловой работы
}

\author{
установки непрерывного литья
}

\section{и прессования алюминия}

в переходном режиме

\author{
А.П. Скуратов, А.С. Потапенко, Ю.В. Горохов \\ Сибирский федеральный университет \\ Россия, 660041, Красноярск, пр. Свободньй, 79
}

\begin{abstract}
Рассмотрены особенности технологического процесса непрерывного литья и прессования цветных металлов. Приведены результаты экспериментального исследования тепловой работы опытно-промышленной установки карусельного типа при непрерывном литье и прессовании технического алюминия. Определен характер и время переходного процесса при холодном пуске установки до достижения стационарных условий ее работьл. На базе программного продукта Ansys CFX разработана трёхмерная компьютерная модель теплообмена в опьтно-промышленной установке. $B$ результате математического моделирования определён необходимый угол поворота кристаллизатора, обеспечивающий при выходе установки на стационарный тепловой режим требуемую по технологии номинальную температуру затвердевания расплава алюминия.
\end{abstract}

Ключевые слова: опытно-промышленная установка, непрерывное литье и прессование, теплообмен, расплав алюминия, затвердевание, эксперимент, компьютерная модель.

\section{Введение}

Достижения в области разработки процессов непрерывного прессования металлов и сплавов подтвердили эффективность замены раздельных линий литейно-прокатных агрегатов на более универсальные установки непрерывного литья и прессования (НЛиП). По этому принципу ведущими зарубежными фирмами изготавливаются и тиражируются линии непрерывного прессования цветных металлов способом Конформ $[1,2]$. Совмещение операций НЛиП в одной установке позволяет существенно снизить металлоемкость производственных линий, повысить их гибкость и степень автоматизации [3-5]. Так, например, непрерывное литье-прессование Кастэкс, где жидкий металл заливается непосредственно в контейнер установки Конформ, является наиболее экономичным способом получения проволоки и профилей по сравнению с их изготовлением из монолитной заготовки [6]. Однако данных по проектированию этого инновационного процесса в настоящее время недостаточно для осуществления стабильного и устойчивого процесса непрерывной кристаллизации жидкого металла в разъемном контейнере. Очевидная перспективность процесса требует его скорейшего внедрения в отечественную промышленность, для чего нужны дальнейшие исследования, направленные, прежде всего, на определение температурно-скоростных условий его осуществления.

В работе представлены результаты экспериментального и теоретического исследования тепловой работы, спроектированной на кафедре обработки металлов давлением Сибирского федерального университета опытно-промышленной установки карусельного типа [7-10] при непрерывном литье и прессовании технического алюминия. 


\section{Результаты испытаний опытно-промышленной установки НЛиП с кристаллизатором карусельного типа}

Согласно имеющимся сведениям, эксплуатация базовой установки Конформ с вертикальным расположением рабочего колеса вызывает определенные затруднения в соблюдении стабилизации подачи металла в инструмент [11]. Связано это, в основном, с периодическим «намораживанием» жидкой фазы расплава на неподвижную часть контейнера при ее затвердевании.

На рис. 1 представлена схема опытно-промышленной установки совмещённого процесса НЛиП цветных металлов с кристаллизатором карусельного типа, позволяющая устранить недостатки конструкции с вертикальным расположением рабочего колеса.

В рассматриваемой установке НЛиП жидкий металл 3 заливается через дозатор 4 в ручей 2 вращающегося рабочего колеса 1 и кристаллизуется до входа в камеру прессования, образованную на участке сопряжения ручья с матрицедержателем 6. Слиток 5 , поступая в камеру прессования, выдавливается в отверстие матрицы 7 в виде пресс-изделия. Процессы заливки жидкого металла в канавку, его кристаллизации и прессования идут непрерывно и при соблюдении указанных выше требований не представляют трудностей.

Температурно-скоростной режим работы установки имеет решающее значение для создания оптимальных условий процесса литья-прессования. С одной стороны, высокая температура прессования может привести к снижению качества пресс-изделий вплоть до появления брака. С другой - слишком низкая температура ведет к повышению сопротивления деформации. Поэтому при выборе температурно-скоростного режима необходимо избегать обоих указанных граничных случаев [9].
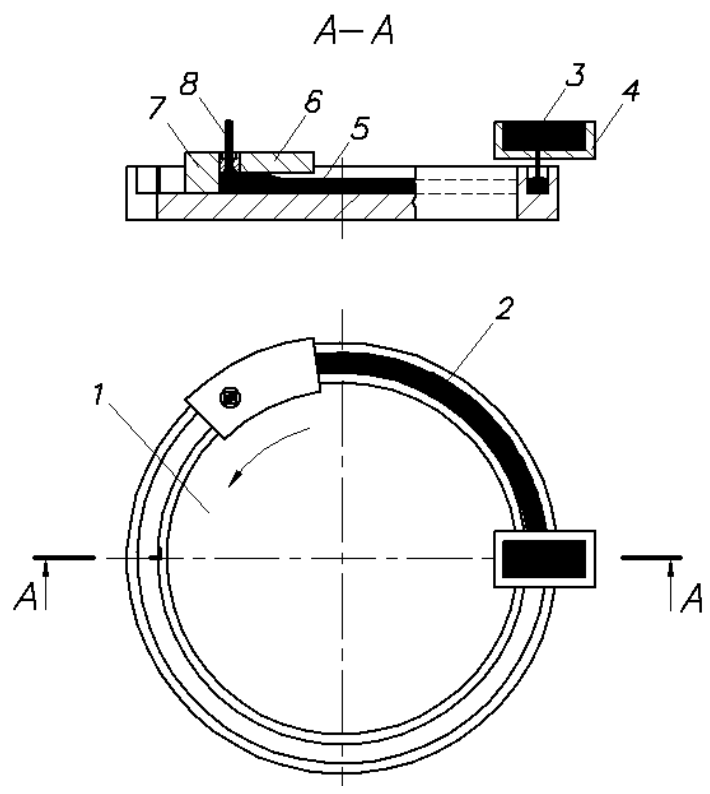

Рис. 1. Схема установки непрерывного литья-прессования цветных металлов: 1 - колесокристаллизатор; 2 - ручей; 3 - жидкий металл; 4 - литниковая коробка;5 - слиток; 6 матрицедержатель; 7 - матрица; 8 - пресс-изделие 
Для НЛиП технологический процесс должен отвечать следующим требованиям: жидкий металл не затвердевает в начальной фазе процесса; скорость перемещения расплава постоянна и соответствует скорости его затвердевания, определяемой интенсивностью теплоотвода от прессового инструмента; в потоке расплава исключена турбулентность; температура металла перед попаданием под пресс-матрицу должна быть на $1-2{ }^{\circ} \mathrm{C}$ ниже номинальной температуры его затвердевания (солидуса).

Натурные исследования тепловой работы опытно-промышленной установки проведены при НЛиП технического алюминия. При этом пресс-матрица была заменена на специальный башмак, в который упирался и в дальнейшем выходил из канавки кристаллизатора застывший расплав. Скорость вращения кристаллизатора составляет два оборота в минуту, температура заливаемого жидкого металла $750{ }^{\circ} \mathrm{C}$, окружающей среды и элементов установки $-20{ }^{\circ} \mathrm{C}$. Для исключения вероятности затвердевания расплава в месте его разливки дозатор и тигель также были нагреты до температуры $750{ }^{\circ} \mathrm{C}$. В ходе эксперимента проводились непрерывные измерения хромель-алюмелевой термопарой температуры металла от места его заливки до башмака, а также температуры кристаллизатора и корпуса установки. Для повышения достоверности результатов исследований была проведена серия из трех опытов при одинаковых начальных условиях.

Результаты измерения температуры затвердевающего металла в процессе пуска установки из холодного состояния (в переходном режиме) представлены на рис. 2.

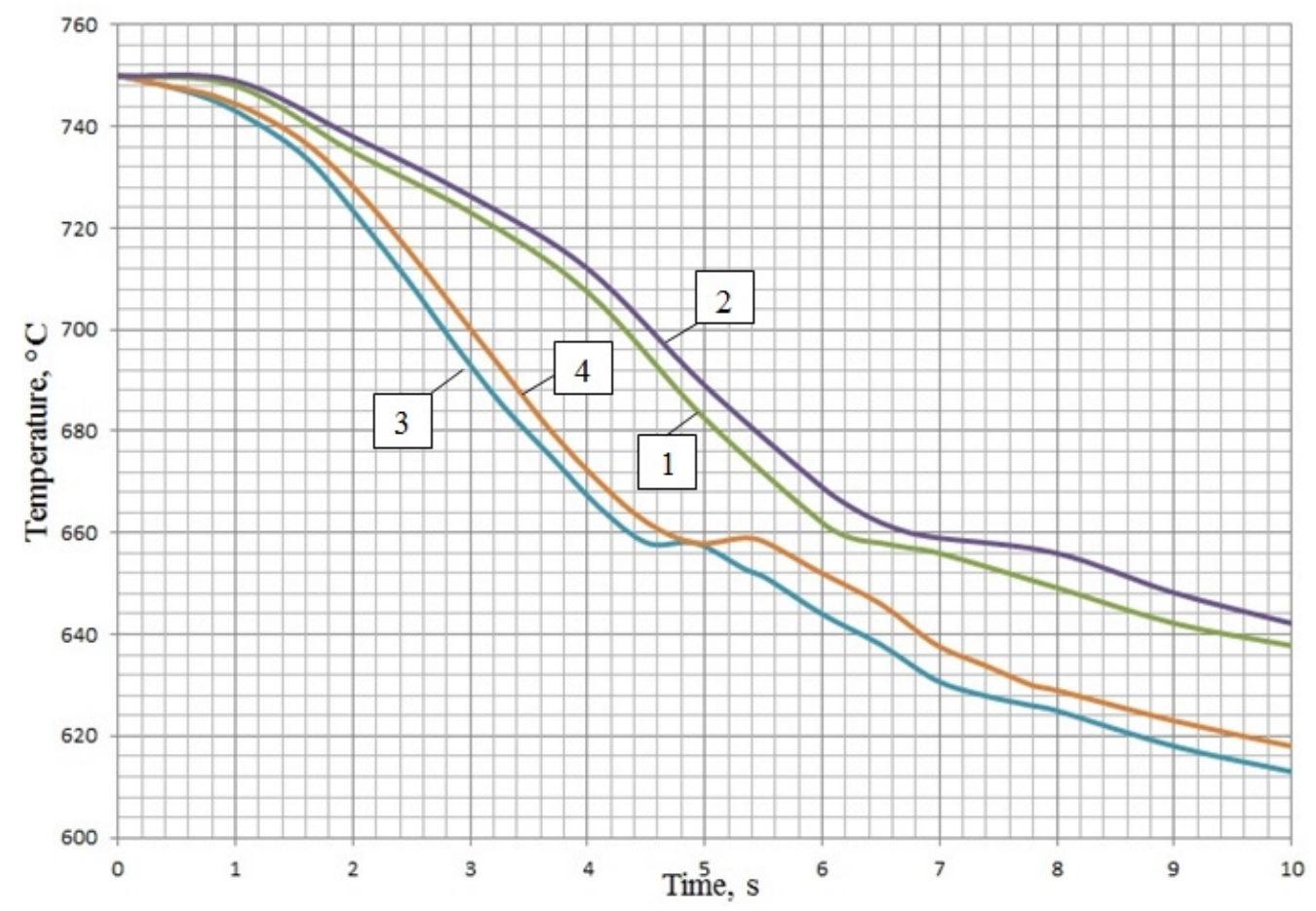

Рис. 2. Динамика изменения температуры затвердевающего металла в переходном режиме: 1 и 2 первый и второй обороты кристаллизатора (эксперимент, опыт № 1); 3 и 4 - первый и второй обороты кристаллизатора (расчет) 
Как видно из графиков охлаждения, при достаточно медленном отводе теплоты от кристаллизатора температура затвердевающего жидкого алюминия монотонно понижается. При этом на кривой охлаждения имеет место характерный небольшой горизонтальный участок, связанный с выделением скрытой теплоты фазового превращения. Далее, после затвердевания металла наблюдается плавное понижение его температуры. Максимальная разница в температуре расплава после первого и второго оборотов кристаллизатора достигает $7{ }^{\circ} \mathrm{C}$ на восьмой секунде после заливки металла при угле его поворота на $\varphi=96^{\circ}$. При этом меняется и координата точки затвердевания металла, которая сдвигается в сторону башмака (рис. 2). Во всех трех опытах определено, что при повороте кристаллизатора на угол $\varphi=84^{\circ}$ после первого оборота и на угол $\varphi=96^{\circ}$ после второго его оборота температура металла достигает точки затвердевания. Отметим, что после холодного пуска (первый оборот кристаллизатора) скорость затвердевания расплава составила $13,3{ }^{\circ} \mathrm{C} / \mathrm{c}$, после его частичного прогрева (второй оборот кристаллизатоpa) $-11,5^{\circ} \mathrm{C} / \mathrm{c}$.

В целом, результаты экспериментов показали, что нестационарный тепловой режим работы установки при ее пуске из холодного состояния связан с постепенным прогревом кристаллизатора и изменением условий отвода теплоты от расплава. Так, например, через 18 и 36 с после холодного пуска установки температура кристаллизатора в окрестности заливки жидкого металла составила соответственно 97 и $105^{\circ} \mathrm{C}$.

\section{Математическое моделирование теплообмена в установке НЛиП}

Задачей моделирования являлась оценка теплового состояния опытно-промышленной установки при НЛиП расплава технического алюминия. Интерес представляло также определение угла $\varphi$, обеспечивающего перед пресс-матрицей номинальную температуру затвердевания по всему сечению металла при стационарном режиме работы установки.

На рис. 3 показана схема трёхмерной компьютерной модели теплообмена в опытнопромышленной установке НЛиП, разработанной на базе программного продукта Ansys CFX.

В расчетах принята упрощенная геометрия расчетной модели: фаски на кристаллизаторе и металле не учитывались (при условии сохранения площади поперечного сечения слитка); отсутствовала матрица, где происходит процесс прессования металла, и тигель с дозатором, через который заливается расплав.

Расплав алюминия заливается в точке кристаллизатора, фиксированной относительно корпуса, и далее за счет его вращения переносится до пресс-матрицы. Для моделирования этого процесса в компьютерной модели задается вращение домена кристаллизатора. При этом домен корпуса остаётся неподвижным. При моделировании переноса расплава граничные условия учитывают: Inlet - подачу жидкого алюминия; Outlet - выход из установки затвердевшего алюминия с тем же массовым расходом.

По условиям задачи домены «корпус» и «кристаллизатор» описываются уравнениями теплопередачи через поверхность, внутри твердого тела решается уравнение теплопроводности. Домен «алюминий» описывается системой уравнений Навье-Стокса для ламинарного течения несжимаемой жидкости и нестационарной теплопроводности $[12,13]$. При этом трехмерное нестационарное уравнение теплопроводности записывалось в виде

$$
-341-
$$




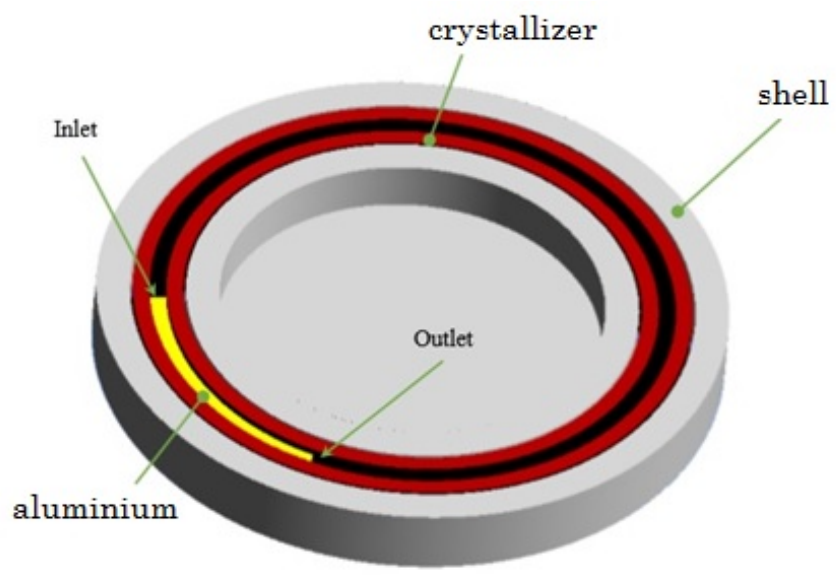

Рис. 3. Схема трехмерной компьютерной модели опытно-промышленной установки непрерывного литья и прессования цветных металлов: aluminium - расплав алюминия; Inlet - вход жидкого алюминия; Outlet - выход затвердевшего алюминия; crystallizer - кристаллизатор; shell - корпус

$$
\Psi(T) \frac{d T}{d t}=a \nabla^{2} T
$$

где $T$ - текущая температура двухфазной зоны сплава, $K ; a$-коэффициент температуропроводности, $\mathrm{m}^{2} / \mathrm{c} ; \psi(T)$ - коэффициент, учитывающий скрытую теплоту кристаллизации расплава $Q$ (кДж/кг):

$$
\begin{aligned}
& \Psi(T)=1+\frac{\mathrm{Q}}{\mathrm{c}(1-\mathrm{k})\left(\mathrm{T}_{K}-\mathrm{T}_{\mathrm{L}}\right)}\left(\frac{\mathrm{T}_{K}-\mathrm{T}_{\mathrm{L}}}{\mathrm{T}_{K}-\mathrm{T}}\right)^{\frac{2-\mathrm{K}}{1-\mathrm{K}}}, \text { при } T_{S} \leq T \leq T_{L} ; \\
& \Psi(T)=1 \text { при } T>T_{L} \text { и } T<T_{S} .
\end{aligned}
$$

Здесь $k$ - коэффициент сегрегации примесей между твердой и жидкой фазой; $T_{K}, T_{L}$ и $T_{S}-$ соответственно температуры кристаллизации, ликвидуса и солидуса сплава, $K$.

При моделировании НЛиП алюминиевого расплава угол поворота кристаллизатора $\varphi$ изменялся в широких пределах. Начальные условия соответствовали проведенному ранее эксперименту: массовый расход расплава 0,007 кг/с (скорость вращения кристаллизатора два оборота в минуту, направление вращения - против часовой стрелки); температуры заливаемого жидкого металла и его затвердевания соответственно 750 и $658^{\circ} \mathrm{C}$, окружающей среды и элементов установки $-20^{\circ} \mathrm{C}$.

Определено, что установка выходит на стационарный тепловой режим работы через $135 \mathrm{c}$ после ее пуска из холодного состояния, что соответствует 5,5 оборотам кристаллизатора. В этом режиме угол $\varphi=93^{\circ}$ обеспечивает перед пресс-матрицей затвердевание металла по всему сечению, перепад температуры в котором не превышает $6{ }^{\circ} \mathrm{C}$ (рис. 4).

Однако расчеты показывают, что после выхода установки на стационарный тепловой режим имеет место существенный перегрев ее элементов (рис. 5).

Так, например, максимальное значение средней по сечению температуры кристаллизатора и корпуса достигает соответственно 629 и $590^{\circ} \mathrm{C}$.

Анализ результатов динамики затвердевания металла, полученных в ходе экспериментов и моделирования, показывает хорошее их качественное совпадение (см. рис. 2). Более интенсив- 


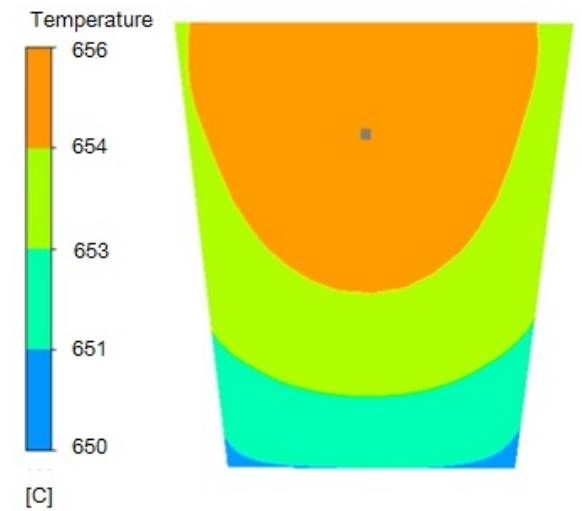

Рис. 4. Температурное поле в расчетном сечении металла при повороте кристаллизатора на $93^{\circ}$ (стационарный тепловой режим)

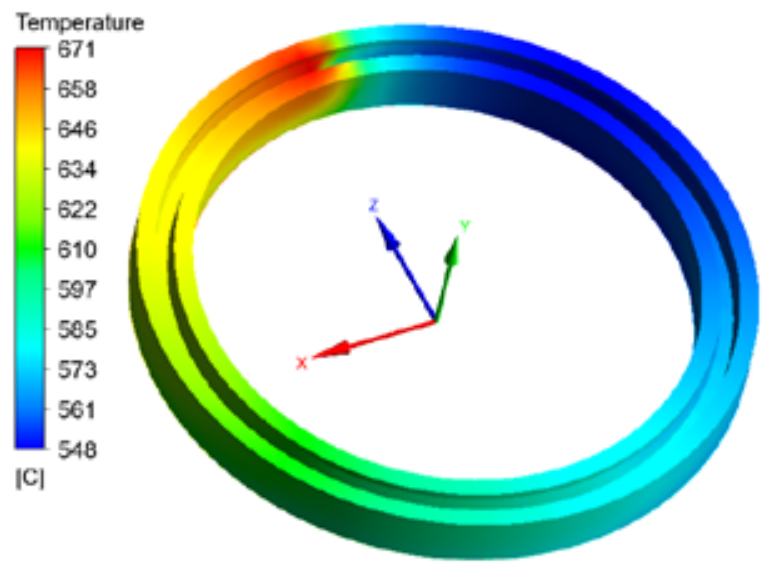

Рис. 5. Температурное поле в кристаллизаторе после выхода установки на стационарный тепловой режим

ный процесс теплообмена имеет место при моделировании: скорость затвердевания расплава составила после первого и второго оборотов кристаллизатора соответственно 19,2 и $17,0{ }^{\circ} \mathrm{C} / \mathrm{c}$, расчетное время затвердевания расплава сократилось в среднем на 1,5 с.

\section{Заключение}

Проведены экспериментальные и расчетные исследования тепловой работы опытнопромышленной установки карусельного типа при непрерывном литье и прессовании технического алюминия. Определен характер и время переходного процесса при холодном пуске установки до достижения стационарных условий ее работы. Установлен необходимый по технологии угол поворота кристаллизатора, обеспечивающий перед пресс-матрицей требуемую по технологии номинальную температуру затвердевания расплава алюминия. Показано, что переходный процесс при холодном пуске установки характеризуется значительным перегревом ее элементов. 
Сравнительный анализ результатов экспериментов и расчетов на разработанной трёхмерной компьютерной модели теплообмена показал на вполне удовлетворительное их согласие и возможность ее использования для дальнейшей отработки надежных условий эксплуатации установки в стационарных и переходных тепловых режимах. При этом полученная в расчетах более быстрая по сравнению с экспериментом скорость затвердевания металла связана как с возможной неточностью в задании условий теплообмена, так и с погрешностью, вызванной тепловой инерционностью термопары.

\section{Список литературы}

[1] Проспект фирмы Holton Machinery Ltd. (UK), 1986. 29.

[2] Проспект фирмы Babcock Wire Equipment Ltd. (UK), 1987. 27.

[3] Сергеев В.М., Горохов Ю.В., Соболев В.В., Нестеров Н.А. Непрерывное литьепрессование иветных металлов. М.: Металлургия, 1990. 85 с. [Sergeev V.M, Gorokhov U.V., Sobolev V.V., Nesterov N.A. Continual casting-extrusion of non-ferrous metals. M.: Metallurgy, 1990. 85 p. (in Russian)]

[4] Шеркунов В.Г., Сергеев В.М., Токарь В.П., Горохов Ю.В. Производство латунной заготовки методом совмещенного литья и непрерывного прессования. Свердловск: КаменскУральский, 1990. 30 с. [Sherkunov V.G., Sergeev V.M., Tokar V.P., Gorokhov U.V. Production of brass perform by means of casting \& continual extrusion. Sverdlovsk: Kamensk-Uralsky, 1990. 30 p. (in Russian)]

[5] Zhou T.G., Jiang Z.Y., Wen J.L., Li H., Tieu A.K. Semi-solid continuous casting-extrusion of AA6201 feed rods. Materials Science and Engineering: A. 2012, 8, 108-114.

[6] Корнилов В.Н. Новые разработки в области непрерывного прессования. Технология легких сплавов, 1990, 11, 60-62 [Kornilov V.N. New investigations in the field of continual extrusion. Technology of the light allows, 1990, 11, 60-62 (in Russian)]

[7] Сергеев В.М., Горохов Ю.В., Шеркунов В.Г. и др. Получение пресс-изделий непрерывным литьем-прессованием. Цветные металлы, 1988, 12, 65-67 [Sergeev V.M., Gorokhov U.V., Sherkunov V.G. et al. Production of press-products with continual casting-extrusion. Non-ferrous metals, 1988, 12, 65-67 (in Russian)]

[8] Горохов Ю.В., Солопко И.В., Константинов И.Л. Основы проектирования конструктивных параметров установки непрерывного литья-прессования металлов. Вестник МГТУ им. Г.И. Носова, 2009, 3, 20-23 [Gorokhov U.V., Solopko I.V., Constantinov I.L. The principles of designing of constructional parameters of metals continual casting-extrusion. Vestnik MGTU, 2009, 3, 20-23 (in Russian)]

[9] Пат. 96798 Российская Федерация, МКП В 21 С 23/08. Устройство для непрерывного прессования. Горохов Ю.В., Черкашин М.А., Крылов М.А.; опубл. 20.08.2010. Бюл. № 23 [Patent 96798 Russian Federation, MKP V 21 S 23/08. Equipment for continual extrusion. Gorokhov U.V., Cherkashin M.A., Krylov M.A.; published 20.08.2010. Newsletter № 23 (in Russian)]

[10] Сидельников С.Б., Горохов Ю.В., Беляев С.В. Инновационные совмещенные технологии при обработке металлов. Журнал Сибирского федерального университета. Серия: Техника и технологии, 2015, 8 (2), 185-191 [Sidelnikov, S.B., Gorokhov U.V., Belyaev S.V. Innovative combined 
technologies for metals processing. Journal of Siberian Federal University. Part: Engineering and technologies, 2015, 8(2), 185-191 (in Russian)]

[11] Kellock B.A Major step forward in aluminium extrusion. Mach. and Prod, 1982 (140), 6, 58-59.

[12] Скуратов А.П., Горохов Ю.В., Потапенко А.С. Расчётное исследование теплового режима установки совмещённого литья и прессования цветных металлов. Сборник докладов VI Международного Конгресса «Цветные металлы и минераль»». Красноярск, 2014, 1133-1140 [Skuratov A.P., Gorokhov U.V., Potapenko A.S. Calculated investigation of thermal mode of an equipment of joint casting and extrusion of non-ferrous metals. Collection of reports of VI International Congress "Non-ferrous metals and minerals". Krasnoyarsk, 2014, 1133-1140 (in Rissian)]

[13] Скуратов А.П., Горохов Ю.В., Потапенко А.С. Применение CAD систем при моделировании тепловых процессов в установке непрерывного литья и прессования цветных металлов. Tруды IV всероссийской научно-практической конференци: Моделирование и наукоемкие информационные технологии в технических и социально-экономических системах. Новокузнецк, 2016, 154-158 [Skuratov A.P., Gorokhov U.V., Potapenko A.S. Applying CAD-systems to model thermal processes in an equipment of continual casting and extrusion of non-ferrous metals. Reports of IV all-russian scientific conference: Modeling and high-tech technologies in technical and socialeconomic systems. Novokusnetsk, 2016, 154-158 (in Russian)] 